\title{
Schema Representation in Patients with Ventromedial PFC Lesions
}

\author{
Vanessa E. Ghosh, ${ }^{1,2}$ Morris Moscovitch, ${ }^{1,2}$ Brenda Melo Colella, ${ }^{3}$ and Asaf Gilboa ${ }^{1,2,4}$ \\ ${ }^{1}$ University of Toronto, Toronto, Ontario M5S 3G3, Canada, ${ }^{2}$ Rotman Research Institute at Baycrest Hospital, Toronto, Ontario M6A 2E1, Canada, ${ }^{3}$ Toronto \\ Rehabilitation Institute, Toronto, Ontario M5G 2A2, Canada, and ${ }^{4}$ Canadian Partnership for Stroke Recovery, Ottawa, Ontario K1G 5Z3, Canada
}

Human neuroimaging and animal studies have recently implicated the ventromedial prefrontal cortex (vmPFC) in memory schema, particularly in facilitating new encoding by existing schemas. In humans, the most conspicuous memory disorder following vmPFC damage is confabulation; strategic retrieval models suggest that aberrant schema activation or reinstatement plays a role in confabulation. This raises the possibility that beyond its role in schema-supported memory encoding, the vmPFC is also implicated in schema reinstatement itself. If that is the case, vmPFC lesions should lead to impaired schema-based operations, even on tasks that do not involve memory acquisition. To test this prediction, ten patients with vmPFC damage, four with present or prior confabulation, and a group of twelve matched healthy controls made speeded yes/no decisions as to whether words were closely related to a schema (a visit to the doctor). Ten minutes later, they repeated the task for a new schema (going to bed) with some words related to the first schema included as lures. Last, they rated the degree to which stimuli were related to the second schema. All four vmPFC patients with present or prior confabulation were impaired in rejecting lures and in classifying stimulus belongingness to the schema, even when they were not lures. Nonconfabulating patients performed comparably to healthy adults with high accuracy, comparable reaction times, and similar ratings. These results show for the first time that damage to the human vmPFC, when associated with confabulation, leads to deficient schema reinstatement, which is likely a prerequisite for schema-mediated memory integration.

Key words: confabulation; lesion study; schema; subgenual anterior cingulate; ventromedial prefrontal cortex

\section{Introduction}

The ventromedial prefrontal cortex (vmPFC) is implicated in schema-supported memory acquisition, retention, and retrieval in rats (Tse et al., 2011; Wang et al., 2012) and humans (Kumaran et al., 2009; Zeithamova and Preston, 2010; van Kesteren et al., 2010). "Schemas" are defined here as adaptable associative networks of knowledge extracted over multiple similar experiences (Ghosh and Gilboa, 2014). Among their functions, schemas provide organizing structures that influence memory formation and retrieval (Piaget, 1926; Bartlett, 1932; Carmichael et al., 1932; Craik and Lockhart, 1972). Evidence for human vmPFC involvement in schema functions rests primarily on neuroimaging and has always focused on schema's effect on subsequent memory tests. A prerequisite for schema-related memory enhancement, however, is that the schema itself is engaged appropriately during processing of novel information. Whether and under what conditions the vmPFC critically supports basic schema engagement is unknown. If it is critically involved, vmPFC lesions should

\footnotetext{
Received Feb. 21, 2014; revised July 21, 2014; accepted July 24, 2014.

Author contributions:V.E.G., M.M., and A.G. designed research;V.E.G. and B.M.C. performed research; V.E.G. and A.G. analyzed data; V.E.G., M.M., B.M.C., and A.G. wrote the paper.

This work was supported by a Natural Sciences and Engineering Research Council of Canada Grant and a Canadian Partnership for Stroke Recovery catalyst Grant to A.G., and a Canadian Institutes of Health Research Grant to M.M. The authors declare no competing financial interests.

Correspondence should be addressed to Dr Asaf Gilboa, 3560 Bathurst Street, Toronto, ON M6A 2E1, Canada. E-mail: agilboa@research.baycrest.org.

DOI:10.1523/JNEUROSCI.0740-14.2014

Copyright $\odot 2014$ the authors $\quad 0270-6474 / 14 / 3412057-14 \$ 15.00 / 0$
}

significantly impair schema-based operations even when memory is not being tested.

The primary memory disorder associated with vmPFC lesions is confabulation, a disorder characterized by erroneous memories without awareness of their falsehood (Korsakoff, 1889; Moscovitch, 1989). Confabulation may arise from strategic retrieval deficits (Moscovitch, 1989; Burgess and Shallice, 1996; Moscovitch and Melo, 1997). By this view, schemas guide memory search by activating relevant cues (Burgess and Shallice, 1996). Moreover, once memories are recovered, monitoring the output depends on its consistency with search schemas (Gilboa, 2004, 2010; Gilboa et al., 2006). Thus, the new evidence implicating the vmPFC in schema functions echoes earlier confabulation models proposing aberrant schema-driven reconstructive processes and suggests a tight relationship between confabulation, vmPFC, and schema.

Experimental paradigms demonstrating vmPFC involvement in schema-facilitated acquisition and retention of new memory always require rapid instantiation of schemas. This raises the possibility that vmPFC is critical not only for schema support of new memory, but for core schema representation and instantiation. We predicted that vmPFC patients who confabulate would have difficulty instantiating task-relevant schemas, and would rely on inappropriately activated schemas, even when memory acquisition was not required. For instance, when visiting the doctor, confabulating patients may activate irrelevant schemas, such as getting ready for bed, leading them to include irrelevant activities, such as looking for materials to brush their teeth. 
Table 1. Group demographic information

\begin{tabular}{|c|c|c|c|c|c|c|c|}
\hline & Gender & Hand & Age (years) & Education (years) & Estimated FSIQ & Chronicity (months) & $\begin{array}{l}\text { Spontaneous confabulation status at time of test- } \\
\text { ing based on clinical observation/family interview }\end{array}$ \\
\hline \multicolumn{8}{|c|}{ Confab $(N=4)$} \\
\hline CP1 & M & $\mathrm{R}$ & 43 & 12 & 86 & 3 & $\begin{array}{l}\text { Florid daily confabulations. Grossly erroneous } \\
\text { memories. Acts upon confabulations; e.g. } \\
\text { claimed to have bought a car, looking for it in } \\
\text { hospital parking lot }\end{array}$ \\
\hline $\mathrm{CP} 2$ & M & $\mathrm{R}$ & 54 & 17 & 99 & 31 & $\begin{array}{l}\text { Daily confabulations. Mostly mild distortions, but } \\
\text { at times severe. Acts upon confabulations; e.g. } \\
\text { described recent US trips that never occurred }\end{array}$ \\
\hline CP3 & M & $\mathrm{R}$ & 39 & 12 & 91 & 1.5 & $\begin{array}{l}\text { Very mild at test. History of significant confabula- } \\
\text { tion. Questionable if ever acted on confabula- } \\
\text { tions; e.g. claimed was laid off work for failing } \\
\text { to fax a paper }\end{array}$ \\
\hline CP4 & M & R & 67 & 14 & 107 & 100 & $\begin{array}{l}\text { Mild confabulations; occurs every few days, but } \\
\text { lacks opportunity because of limited social } \\
\text { interaction; e.g. recalled trips to Brazil and } \\
\text { Japan (never happened) }\end{array}$ \\
\hline$A v g$ (SD) & $4 \mathrm{M}$ & $4 R$ & $50.75(12.55)$ & $13.75(2.36)$ & $95.75(9.21)$ & $33.88(46.12)$ & \\
\hline \multicolumn{8}{|c|}{$\mathrm{ACOA}(N=6)$} \\
\hline P1 & M & L & 43 & 12 & 116 & 39 & NA \\
\hline P2 & $\mathrm{F}$ & R & 59 & 13 & 105 & 1.5 & NA \\
\hline P3 & $\mathrm{F}$ & R & 61 & 15 & 114 & 53 & NA \\
\hline P4 & $\mathrm{F}$ & $\mathrm{R}$ & 56 & 15 & 114 & 46 & NA \\
\hline P5 & $\mathrm{F}$ & $\mathrm{R}$ & 56 & 14 & 91 & 57 & NA \\
\hline P6 & M & $\mathrm{R}$ & 53 & 13 & 99 & 10 & NA \\
\hline $\operatorname{Avg}(S D)$ & $2 \mathrm{M} / 4 \mathrm{~F}$ & $5 \mathrm{R} / 1 \mathrm{~L}$ & 54.67 (6.34) & $13.83(1.33)$ & $106.50(10.02)$ & $34.41(23.20)$ & \\
\hline \multicolumn{8}{|c|}{ Controls (N=12) } \\
\hline Avg (SD) & $6 \mathrm{M} / 6 \mathrm{~F}$ & $11 \mathrm{R} / 1 \mathrm{~L}$ & $53.17(7.71)$ & $14.75(1.22)$ & $112.33(4.34)$ & NA & \\
\hline
\end{tabular}

FSIQ was calculated according to Wechsler (2001).

To determine whether the human vmPFC is necessary for instantiating appropriate schemas, regardless of memory demands, we tested whether vmPFC patients can identify the belongingness of concepts to pre-existing schemas (e.g., "syringe" is relevant to "visiting the doctor" but "toothpaste" is not), and whether a recently activated, but no longer relevant schema, influences performance. Importantly, the task did not tax episodic memory processes, and thus was not confounded by encoding or retrieval deficits. The paradigm required only on-line processing and reliance on long-term schema representations. We also tested whether schema instantiation deficits are specifically associated with confabulation or whether they also arise in nonconfabulating vmPFC patients, because the two groups have different patterns of deficits on other tests (Gilboa et al., 2006).

\section{Materials and Methods}

Participants

Patients. Ten patients ( 6 male, 4 female) with lesions to the vmPFC were tested. All patients had acquired brain damage following rupture of an anterior communicating artery $(\mathrm{ACoA})$ aneurysm. The patients were recruited from the Baycrest Hospital Psychology Department, the Rotman Research Institute's patient registry, and the Toronto Rehabilitation Institute (TRI) Acquired Brain Injury Neurorehabilitation Program; all research procedures were approved by the institutes' Research Ethics Boards. Note that the patient sample was recruited solely based on lesion location and etiology. All ACoA aneurysm rupture patients who came through TRI were targeted for recruitment, as well as all individuals who were part of the research patient registry at Baycrest Hospital who could be contacted. Presence of confabulation was assessed after study enrollment. Only one patient, CP4, was contacted based on not only lesion location and etiology, but also for known tendency to confabulate when tested for a previous study, as reported by Gilboa et al. (2006), where this patient was identified as "SH." Patients reported to confabulate based on their clinical files and qualitative reports from family members and clin- ical staff are denoted as CP1, CP2, CP3, and CP4. Note that CP3 was deemed by family members to have a confabulation history, but was no longer confabulating at the time of study. Nonconfabulating patients are denoted as P1-P6.

Table 1 presents demographic information of the three groups. A Kruskal-Wallis $\mathrm{H}$ test was performed to establish whether the groups differed in terms of demographic variables. Age did not differ significantly across the groups $\left(H_{(2)}, p=0.761\right)$, nor did years of education $\left(H_{(2)}, p=0.295\right)$, or in the case of the patient groups, the months since aneurysm rupture $\left(H_{(1)}, p=0.657\right)$. Full Scale Intelligence Quotient (FSIQ) as measured by the Wechsler Test of Adult Reading (Wechsler, 2001) was not matched $\left(H_{(2)}, p=0.023\right)$.

Table 2 presents the patients' performance on a battery of neuropsychological tests. Patients demonstrated significant deficits in memory and executive functions. To explore possible differences between confabulating patients and nonconfabulating ACoA patients on general executive and memory functioning, a "composite executive score" and a "composite memory score" were computed for each patient (Fig. 1). The former was the average Z-score on verbal fluency, Trail Making Task (TMT) B:A ratio, digit span backwards, and Stroop interference. The memory score was the average Z-score on delayed recall on the ReyOsterrieth Complex Figure, California Verbal Learning Test (CVLT-II) immediate free recall, and CVLT-II long delayed free recall. Confabulating patients, except for $\mathrm{CP} 2$, were in the lower range in terms of executive functioning, consistent with previous findings on the association between executive function and confabulation (Kapur and Coughlan, 1980). Memory scores were comparable across the two patient groups, with the exception of $\mathrm{P} 4$ who demonstrated superior memory relative to the other patients, and CP1 and P9 who had average memory scores.

Patients with current or prior confabulation. CP1 had begun to confabulate immediately following his aneurysm's rupture. CP1 had a history of severe chronic headaches resulting in morphine dependence that was treated with methadone. Additionally, he was taking antidepressant medication but was not depressed at the time of testing. 
Table 2. Patient standard scores (Z-scores) on neuropsychological tests

\begin{tabular}{|c|c|c|c|c|c|c|c|c|c|c|c|}
\hline Test & CP1 & CP2 & CP3 & CP4 & P1 & P2 & P3 & P4 & P5 & P6 & Norm reference \\
\hline Rey-Osterrieth Complex Figure & & & & & & & & & & & (Fastenau et al., 1999) \\
\hline Copy & 0.70 & 0.29 & 0.37 & - & 0.05 & 0.86 & -1.17 & 0.63 & 0.95 & 0.84 & \\
\hline Immediate recall & -0.71 & $*-2.54$ & $*-2.06$ & $-0.81^{a}$ & $*-2.73$ & -1.16 & -1.46 & 1.31 & -0.99 & 1.14 & \\
\hline Delayed recall & -0.31 & $*-2.46$ & -1.96 & - & $*-2.64$ & -0.89 & -1.17 & 1.24 & -0.97 & 1.32 & \\
\hline California Verbal Learning Test & & & & & & & & & & & (Delis et al., 1988) \\
\hline List A trials 1-5, free recall & -0.4 & $*-2.3$ & $*-2.3$ & -1.7 & $*-2.7$ & $*-2.5$ & -1.6 & 1.1 & $*-2.8$ & -0.6 & \\
\hline List $B$, free recall & -0.5 & -1.5 & -0.5 & -1.5 & -1.5 & -1.0 & -1.5 & -1.0 & -1.5 & -2.0 & \\
\hline List A, short delay free recall & -1.5 & $*-3.0$ & $*-3.0$ & $*-2.5$ & $*-3.0$ & $*-3.5$ & $*-3.0$ & 0.5 & $*-3.5$ & 0.0 & \\
\hline List A, short delay cued recall & -1.0 & -1.5 & $*-3.0$ & $*-3.0$ & $*-4.0$ & $*-4.0$ & $*-3.5$ & 0.5 & $*-2.5$ & 0.0 & \\
\hline List A, long delay free recall & -1.0 & $*-2.5$ & $*-3.0$ & $*-2.5$ & $*-3.5$ & $*-4.0$ & $*-3.0$ & 1.5 & $*-4.0$ & 0.0 & \\
\hline List A, long delay cued recall & -1.0 & ${ }^{*}-3.0$ & $*-2.5$ & $*-2.5$ & $*-3.5$ & $*-3.5$ & $*-3.5$ & 0.5 & $*-3.5$ & -1.0 & \\
\hline Free recall intrusions & $* 4.0$ & -1.0 & 1.0 & 0.0 & 0.0 & 0.5 & 1.0 & -1.0 & 1.5 & -0.5 & \\
\hline Cued recall intrusions & $* 5.0$ & *2.5 & 0.5 & -0.5 & $* 5.0$ & $* 2.5$ & *4.0 & -0.5 & 1.5 & 1.0 & \\
\hline Total Repetitions & 0.5 & -1.0 & -0.5 & -1.0 & -1.0 & -1.0 & 0.0 & -1.0 & 0.5 & -0.5 & \\
\hline Yes/No Hits & 0 & $*-2.5$ & -1.5 & -1.0 & $*-4.0$ & -1.0 & $*-3.0$ & 0.5 & $*-4.0$ & 0.5 & \\
\hline Yes/No False Alarms & $* 2.0$ & $* 5.0$ & $* 2.5$ & 1.5 & *4.5 & *4.0 & $* 4.0$ & -0.5 & 1.0 & 0.5 & \\
\hline Semantic Clustering & 0 & -0.5 & -0.5 & -0.5 & 0.0 & 0.0 & -1.0 & -1.5 & -0.5 & -0.5 & \\
\hline Serial Clustering Forward & -1.0 & 0.5 & 0.0 & -0.5 & 0.5 & 0.0 & 0.5 & $* 4.5$ & 0.0 & 0.5 & \\
\hline Serial Clustering Bidirectional & -1.5 & 1.0 & -0.5 & -0.5 & 0.0 & -0.5 & 0.5 & $* 5.0$ & 0.0 & 0.0 & \\
\hline Subjective Clustering & -1.0 & 0.5 & -1.5 & 0.0 & -1.0 & 1.5 & -1.0 & $* 5.0$ & -1.5 & -0.5 & \\
\hline Trail making task & & & & & & & & & & & (Perianez, 2007) \\
\hline TMT A & *4.05 & *3.68 & -0.51 & 0.31 & 0.38 & -0.71 & -0.45 & -0.36 & -0.55 & *2.46 & \\
\hline TMT B & *2.88 & *3.77 & -0.14 & 0.38 & 0.40 & -0.36 & -0.58 & -0.32 & -0.66 & $* 5.08$ & \\
\hline B-A & $* 2.12$ & *2.47 & -0.02 & 0.48 & -0.57 & -0.04 & -0.78 & -0.30 & -0.83 & *4.65 & \\
\hline $\mathrm{B}: \mathrm{A}$ & 0.47 & 0.04 & -0.22 & 0.00 & -0.78 & 0.31 & -0.15 & 0.10 & -0.09 & 1.58 & \\
\hline$B-A / A$ & 0.47 & 0.04 & -0.22 & -0.01 & -0.78 & 0.31 & -0.29 & 0.19 & -0.18 & 1.58 & \\
\hline Digit span & & & & & & & & & & & (Wechsler, 2008) \\
\hline Forwards & -1.29 & -0.57 & -0.57 & -1.15 & -0.57 & 1.15 & 1.23 & 1.23 & -1.07 & $*-2.00$ & \\
\hline Backwards & -1.93 & -1.2 & 0.73 & -0.38 & 0.73 & 0.38 & -0.38 & 1.15 & -0.38 & -1.20 & \\
\hline 45 s Stroop & & & & & & & & & & & (Golden, 1978) \\
\hline Words & -1.5 & -1.0 & -0.5 & -0.8 & 0.5 & -0.4 & 0.0 & 0.9 & -0.6 & -1.7 & \\
\hline Colours & -0.9 & -1.2 & -0.5 & -0.7 & 1.3 & 0.0 & *2.7 & 0.1 & -0.7 & $*-3.2$ & \\
\hline Colour of Words & -0.6 & -1.2 & 1.1 & -0.4 & 1.8 & -0.5 & 1.0 & 1.5 & 0.8 & $*-2.4$ & \\
\hline Interference & 0.2 & -0.3 & 1.4 & 0.2 & 0.9 & -0.4 & -0.2 & 1.1 & 1.3 & 0.2 & \\
\hline Verbal fluency & & & & & & & & & & & (Tombaugh et al., 1999) \\
\hline FAS & -1.17 & -1.67 & -1.07 & -1.65 & -0.05 & 0.12 & $* 2.81$ & 1.54 & 0.03 & $*-2.65$ & \\
\hline Animals & -0.19 & -0.72 & -1.38 & -0.76 & 1.48 & -0.72 & 1.38 & 0.94 & -0.54 & $*-2.57$ & \\
\hline
\end{tabular}

*Denotes moderate to severe impairment.

${ }^{a}$ Camden Topographical Memory Recognition test (Warrington, 1996) Z-score.

CP2 was taking medication to treat hypertension. CP2's brother reported that the family first noticed his confabulations $\sim 6$ months following his aneurysm's rupture. CP2 still demonstrated confabulation at testing.

CP3 was taking Dilantin, an anti-epileptic drug, and medication to treat hypertension. At the time of testing, his affect was labile, frequently fluctuating between laughing and crying. Based on his clinical file and reports from his spouse, it was determined that CP3 had begun to confabulate immediately following his recent aneurysm and that he demonstrated only mild confabulation, if any, at the time of testing.

CP4 was specifically approached because of his documented history of confabulation (Gilboa et al., 2006) to increase the number of confabulating patients in the study, unlike other patients in the study who represent an exhaustive recruitment effort from Baycrest and TRI, using our exclusion criteria. Since he last participated in research, CP4 had one additional major medical incident in 2012 where he was found unconscious alone in his apartment. A suspected diagnosis of acute petrous apicitis was noted in his medical form. Additional cerebrovascular or other neurological accidents were ruled out. At the time of the current testing, $\mathrm{CP} 4$ was residing in a long-term care facility and was still confabulating. He was not taking any medication.

There are several different sets of criteria and classifications that have been proposed for confabulation (Berlyne, 1972; Kopelman, 1987; Schnider et al., 1996; Burgess and McNeil, 1999). Each of the four patients with present or former confabulation met several of these sets of criteria. For instance, $\mathrm{CP} 1$ and $\mathrm{CP} 2$ and possibly $\mathrm{CP} 4$ could be regarded as spontaneous behavioral confabulators as defined by Schnider et al. (1996) because of their frequent tendency to act based on erroneous memories. All four of these patients could also have been considered spontaneous confabulators (at testing, or formerly in the case of CP3) as defined by Kopelman (1987), because they confabulated without any apparent prompting (a definition that is broader than that of Schnider et al. (1996), and encompasses both behavioral and verbal confabulations).

Although all four patients presently, or formerly, confabulated floridly and spontaneously, and some of their confabulations were highly improbable given the situation, the content of their confabulation was not bizarre or fantastic as defined by Berlyne (1972). Some of CP2's confabulations could be characterized as being driven by habits or schematic generic representation of the self (Burgess and McNeil, 1999), as he would describe in conversation having recently encountered a problem at work which had in fact not occurred (as he was no longer working by the time of testing), but which was similar to the types of problems that would have arisen when he had been employed.

Finally, as shown in the Modified Crovitz cue-word test section, at the time of testing these four patients varied greatly in terms of their scores on erroneous details in response to an experimental measure of provoked confabulation. CP1 demonstrated an extremely high score. CP2 and CP4 also had high scores, although not as extreme as that of CP1. CP3, the former confabulator, had a rather low incidence of erroneous details on this measure, which supports the qualitative report that he had a history of confabulations, rather than current confabulation. Erroneous details 


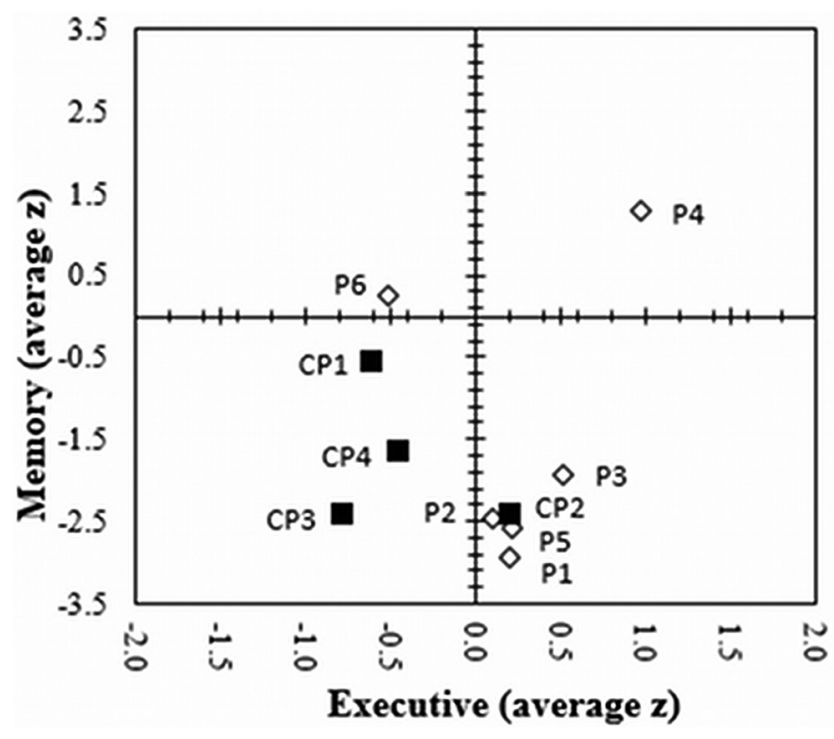

Figure 1. Patients' composite Z-scores for memory and executive functioning. Black squares represent $A C O A$ patients with present or former confabulation. White diamonds represent $A C O A$ patients without any history of confabulation. Note that for CP4 the Z-score on the Camden Topographical Recognition test was used in place of the delayed score on the Rey Figure in computing his composite memory score.

on this measure are formally considered provoked (Kopelman, 1987; Schnider et al., 1996) or momentary (Berlyne, 1972) confabulations, and are thought to be dissociable from spontaneous confabulation. We did not rely on these erroneous memories to determine the patients' confabulatory status. However, many studies have primarily relied on such measures for identifying confabulation (Moscovitch and Melo, 1997; Nedjam et al., 2000) or have used them in combination with clinical observations as criteria for inclusion (Kan et al., 2010). Similar to these other studies, we consider the frequency and quality of erroneous details provided in such measures to be indicative of confabulation quality or floridness, although not diagnostic of it.

Patients without a history of confabulation. P1 could not recall instances that had occurred a few minutes prior, and thus repeatedly asked the experimenter for clarification as to where he was and what he was doing. He had been diagnosed with depression, which was controlled by antidepressant medication at the time of testing.

P2 had undergone previous aneurysm ruptures to the middle cerebral artery and posterior communicating artery a year before the ACoA rupture. Her sister described that since the aneurysm rupture, P2 appeared to have difficulty creating new memories. She had a history of fibromyalgia and was taking acetaminophen at the time of testing.

P3's spouse explained that P3 appears to have intact remote memory, but will forget recent events, such as what she had eaten for breakfast earlier that day. She was not taking medication at the time of testing.

$\mathrm{P} 4$ has been diagnosed with depression for which she was taking antidepressant medication at the time of testing.

P5 was not taking medication at the time of testing.

P6 was taking medication to lower his cholesterol at the time of testing. Matched control group. Twelve healthy controls were also tested (6 male and 6 female), matched to the patient groups for age, sex, and years of education (Table 1). These healthy participants were recruited from the Rotman Research Institute's healthy volunteer pool. Exclusion criteria for healthy controls included learning English after the age of 6 years and any diagnosis of neurological disorders, psychiatric disorders, or systemic disorders (e.g., diabetes, alcoholism).

\section{Behavioral experimental task}

There were three parts to the task. The first two parts each consisted of a schema title ("visit to the doctor" and "going to bed at night") and subjects were asked to imagine the scenario. They were then presented with words on a monitor and asked to decide whether they belonged to that schema or not. In the third part, participants rated the degree to which words were associated with the schema that had been tested in Part 2.

Task stimuli. The experimental stimuli consisted of two stimulus types in Part 1 (current schema words, irrelevant words) and four stimulus types in Parts 2 and 3 [current schema words, irrelevant words, previous schema words (old), previous schema words (new)]. The words were chosen based on a pilot study. Twenty-two participants completed a questionnaire in which they were asked to rate the degree to which 300 words were associated with the experience of "a visit to the doctor" on a scale of 1 ("not at all related") to 4 ("highly related"). In addition, as part of this pilot, these same participants rated the degree to which the same 300 words were associated with the experience of "going to bed at night" on the same scale. Words were considered relevant to "going to bed at night" or to "going to the doctor" if their mean rating was $>2.5$ for the relevant schema and $<1.5$ for the other schema. This was done to ensure that the overlap between the schemas was as small as possible.

Task procedure. In Part 1, participants were first asked to close their eyes for 30 s to imagine the schema for "going to bed at night." This was done to activate the schema. They were told: "Think about what it is like when you go to bed at night. Try to imagine the sequence of events that occur when getting ready for bed and the environment when you are in bed." Participants were next seated at a computer and told that they would see words appear on the monitor. They were asked to respond "yes" (left click) if the word that appeared on a given trial was associated with going to bed, and "no" (right click) if the word that appeared was not associated with that schema. Stimulus presentation and response recordings were controlled by E-prime 1.2 (www.pstnet.com).

Words appeared in white in the center of a black screen and were displayed until participants responded using the mouse. The next word appeared following a 500 millisecond interstimulus interval. Response accuracy and response latency were recorded across this part of the task. A prompt of the question was displayed throughout the task to prevent participants from forgetting the task instructions (e.g., "Is the following word closely associated with GOING TO BED AT NIGHT?"). Similarly, prompts remained on the screen that indicated which mouse click (left or right) corresponded with a "yes" response, and which corresponded with "no." Following Part 1, there was a 10 min break before the administration of Part 2 of the task, during which nonlinguistic neuropsychological tests were administered.

Part 2 of the task progressed exactly as in Part 1, except that participants were told to imagine a new schema: "a visit to the doctor." They were instructed to first imagine the schema for $30 \mathrm{~s}$ as follows: "Think about what it is like when you visit the doctor. Try to imagine the environment when you are there, the people you encounter, and the sequence of events that occur." The behavior required of the participants was the same as in Part 1, except that participants were required to indicate whether the words that appeared were associated with this new schema.

Part 3 immediately followed Part 2. In this part of the task, participants were presented with the same stimuli as in Part 2 and were asked to rate the degree to which each word was associated with the "doctor" schema. Again, a prompt of the question was displayed throughout the task (e.g., "To what degree is the following word associated with A VISIT TO THE DOCTOR?"). They were instructed to rate the association on a 4-point scale, where "1" represented a "high" association, whereas "4" represented a "weak" association. The value of 1 was selected to represent a high association, because it is located to the left of the response pad, and also corresponded well with a "left click" formerly representing "yes" to the question of association. These ratings were included to measure gradation rather than categorical decisions regarding the relevance of the words to the patients' representation of schemas. Ratings were only included after Part 2 as this provided an opportunity to measure inclusion of previous schema words in the schema in question, whereas ratings following Part 1 would not. Furthermore, requesting ratings following Part 1 would have doubled the presentation frequency of Part 1 schema words before performing Part 2.

The study was set up as multiple single case studies, comparing ten patients with overlapping damage to the vmPFC. Due to the small sample 

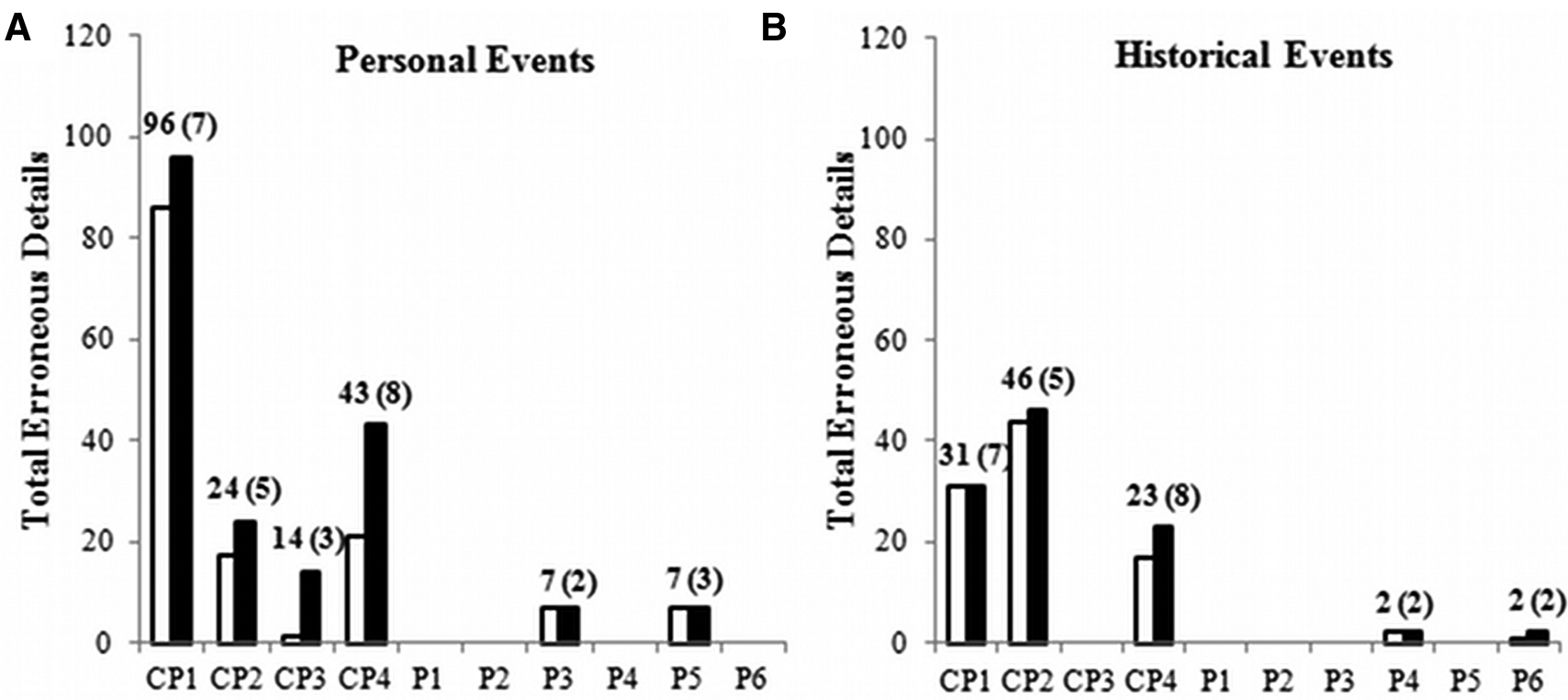

Figure 2. Total erroneous details reported by each patient across the 12 personal $(\boldsymbol{A})$ and 12 historical $(\boldsymbol{B})$ cue words of the Crovitz cue-word test. Values above the bars represent the number of erroneous details in the full response, and values in brackets represent the number of words eliciting erroneous details out of 12 . White bars represent the response preprompting, whereas black bars represent the full response.

Table 3. Number of cues eliciting responses

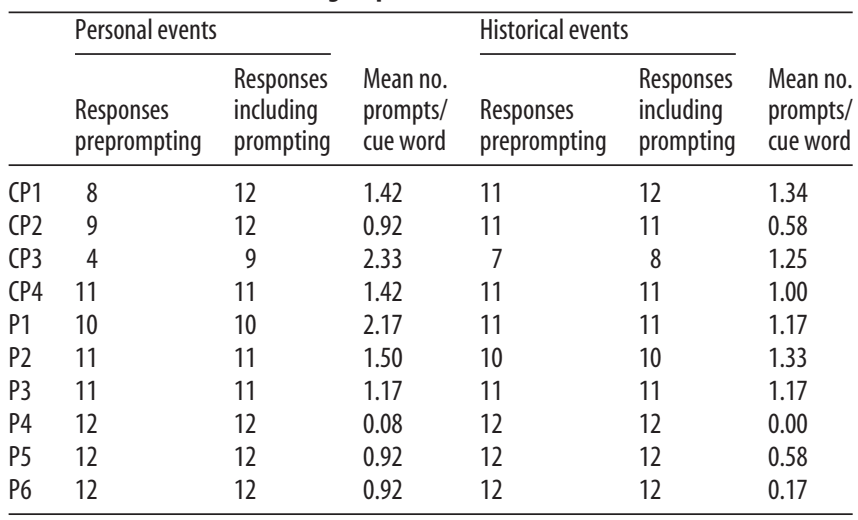

sizes, the order of schema presentation could not be counter-balanced across participants.

\section{Modified Crovitz cue-word test}

The patients' history of confabulation was determined based on their clinical record and was also quantified through a modified Crovitz cueword test (Moscovitch and Melo, 1997). This task was administered to all of the patients. The test measures the number of erroneous details produced while participants recall either semantic or episodic information in response to cue words. The test was also used to provide a measure of the degree of detail of episodic autobiographical memory.

For the modified Crovitz cue-word test, participants were first asked to describe a personal event of which they were reminded when presented with each of 12 cue words. In a subsequent condition, they were asked to describe a historical event that occurred before they were born of which they were reminded when presented with 12 additional cue words. It is important to note that the Crovitz cue-word test was only intended to supplement the clear clinical observations of CP1, CP2, CP3, and CP4's current or former propensity to confabulate. As with all experimental measures of confabulation, the memories produced are to some degree provoked. Note, however, that the quantity and quality of provoked confabulations produced in response to this kind of direct questioning tend to be more elaborate and embellished in spontaneous confabulators, as is evident in $\mathrm{CP} 1, \mathrm{CP} 2$, and CP4's responses. This difficulty in experimentally measuring spontaneous confabulation was previously noted (Kopelman, 1987; Schnider et al., 1996; Gilboa et al., 2006; Gilboa and Verfaellie, 2010).

If the participant did not provide information or gave vague responses, then the cue word was repeated within a question. For example, if the word was "angry," they might be asked, "Can you remember a time when you or someone you know was angry?" This initial rephrasing was not considered to be a prompt in later pre/postprompt calculations. If additional prompts were needed, general, rather than specific, prompting was used (e.g., "Can you provide any other details?" or "Could you describe a specific event?"). The nonspecific nature of these questions differs from the means of administration described by Moscovitch and Melo (1997) and was implemented to minimize provoked confabulations, on the one hand, but maximize the probability of obtaining some response, on the other.

For the measure of autobiographical memory integrity, each response to cues for personal events was segmented into informational bits or details. Similarly to Levine et al. (2002), a detail was defined as a unique occurrence, observation, or thought, typically expressed as a grammatical clause (i.e., a subject and predicate). Additional information in the clause was scored separately. In cases where participants quoted dialogue from a specific conversation, all statements said by one individual before switching speakers were counted collectively as only one detail. The subsequent line said by the next speaker was counted as a detail, and a further statement said by the first speaker was counted as a new detail, and so on. Repetitions or editorializations (e.g., "That wasn't a good idea”) were removed from scoring. Each remaining detail was identified as either an "episodic detail" or a "semantic informational bit". Episodic details were those that were specific to a particular time and place. Semantic informational bits pertained to factual information or extended events that do not require recollection of a specific time and place (e.g., "I used to play football").

Confabulation scores were determined by assigning a score of " 1 " to each incorrect episodic detail or semantic informational bit. For historical events, responses were segmented in the same manner as for personal events. Historical accounts were verified through the Internet. If an account of an event was corroborated by a source on the Internet, then it was not considered a confabulation. Personal event accounts were verified by contacting family members and friends. If these individuals could not verify or refute a particular event, nor was there a suitable alternative for verification, then the patients themselves were prompted to redescribe the event in a follow-up session 1 month after the initial testing. This procedure was used for four events described by $\mathrm{CP} 1$, five events 

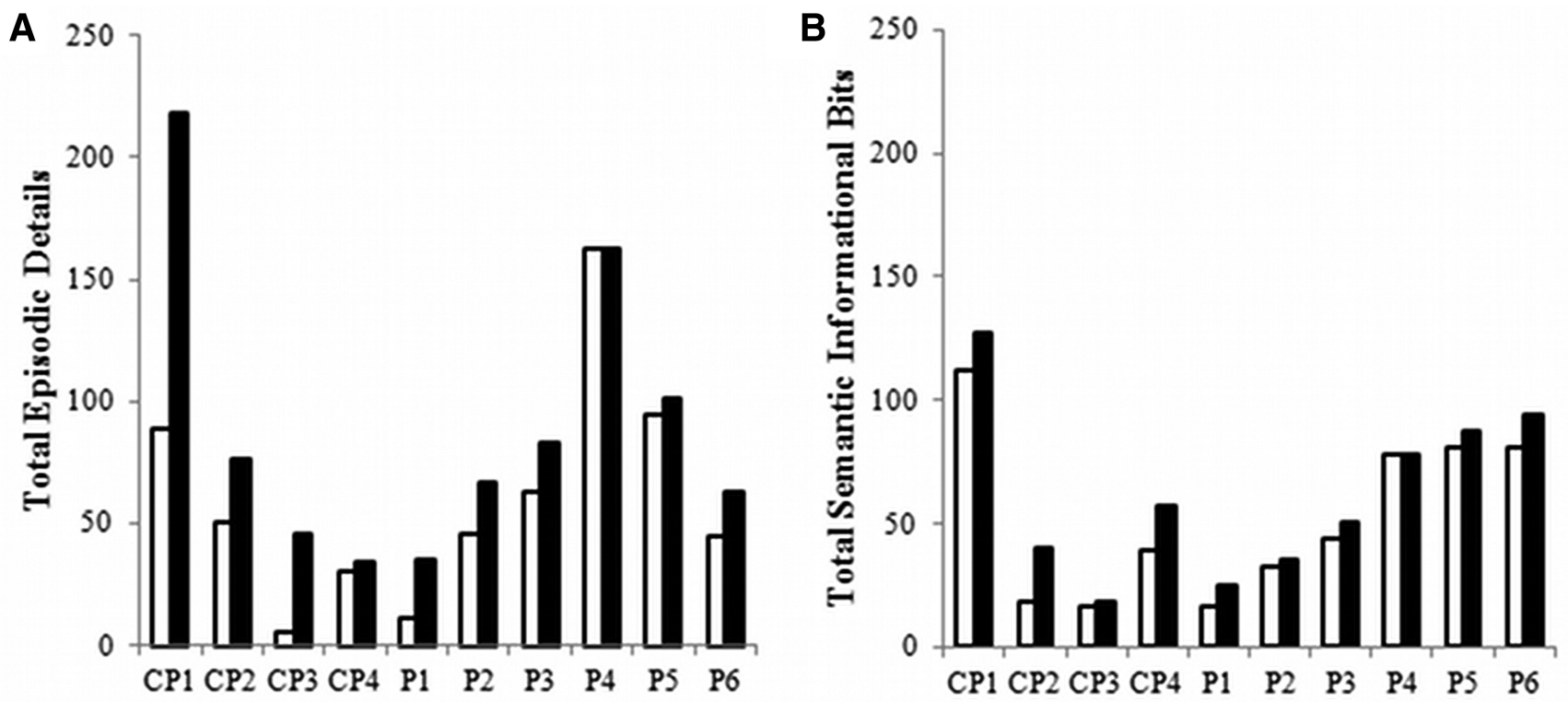

Figure 3. $\boldsymbol{A}$, Total number of accurate episodic details reported by each patient across the 12 personal event accounts given in the Crovitz cue-word test. $\boldsymbol{B}$, Total number of accurate semantic informational bits reported by each patient across the 12 personal event accounts given in the Crovitz cue-word test. White bars represent the response preprompting, whereas black bars represent the full response.

described by P2, seven events described by $\mathrm{P} 4$, and three events described by P6. In all cases, the new account was congruent with the original information, and thus to err on the side of caution they were not deemed confabulations.

Confabulations. The four patients deemed to confabulate based on reports from clinical staff and family, and based on clinical observations at testing, did include erroneous details in their accounts of personal events, and in the case of CP1, CP2, and CP4, also in their accounts of historical events (Fig. 2). In conjunction with CP3's spouse's reports, it appears that his degree of confabulation significantly decreased since the time of his aneurysm rupture, but he still had occasional spontaneous confabulations. Also of note, some of the other ACoA patients included a few erroneous details in their accounts. However, without any evidence of spontaneous confabulation, they were not included in the confabulation group based on their provoked confabulations in the Crovitz task. Note that healthy adults also sometimes include a minimal number of erroneous details on this task (Moscovitch and Melo, 1997). There was no correlation between number of prompts provided and number of erroneous details. Table 3 shows the number of cues to which responses were given before and after prompting. As depicted in Figure 3, prompting primarily increased the proportion of accurate details that were episodic, relative to those that were semantic in nature. It is also of note that contrary to Moscovitch and Melo (1997) where prompting led to significant increases in both veridical and confabulatory responses, in the current study the main increase was in veridical details. This may be related to the more general, nonspecific, nature of the probe used in the present investigation.

\section{Lesion overlap}

Clinical computed tomography and/or MRI scans were obtained for the four confabulating patients and six nonconfabulating ACoA patients. A procedure based on Damasio and Damasio (1989) was used for identifying which frontal lobe regions sustained lesions. However, rather than the standard Brodmann areas, we used the more refined Petrides and Pandya (2002) architectonic divisions for the frontal lobes (Stuss et al., 2002). We identified the specific frontal regions that were damaged in each patient (Fig. 4) by superimposing their individual scans on a brain template. Lesions were drawn by V.E.G. and verified by A.G.

When identifying lesions in scans with a surgical clip present, artifacts produced by the clip make it difficult to observe damaged tissue. In these cases, if damage was evident directly above and directly below the slices containing clip artifacts, then it was extrapolated that the lesion also included the region occupied by the clip. Note that damage in the areas surrounding the clip was assessed based on the original image slices directly above and below the clip, where these slices may not be included in the brain template depicted in Figures 4 and 5.

Figure 5 provides an indication of the lesion overlap of $\mathrm{CP} 1, \mathrm{CP} 2, \mathrm{CP} 3$, and $\mathrm{CP} 4$, as well as a separate indication of the lesion overlap of P1-P6. The area of overlap for the four patients with present or former confabulation corresponds to the subgenual cingulate cortex (BA24/BA25), which has previously been hypothesized to be critical for production of confabulation (Gilboa and Moscovitch, 2002; Schnider, 2003; Turner et al., 2008). Note, however, that lesions to that region also occurred in nonconfabulating patients (P1, P4, and P5), suggesting damage to the subgenual vmPFC may be necessary, but not sufficient, to produce confabulation.

\section{Results}

Analyses were conducted as multiple single case studies, where each ACoA patient was compared with the matched control group on each of the task measures. Confabulating and nonconfabulating patients were not treated as groups in the statistical measures because such treatment would obscure important individual differences among patients.

\section{Reaction time}

For all participants, reaction times to particular words were removed from analysis if they exceeded 2.5 SDs above the mean reaction time for that particular type of stimulus for that individual. Number of reaction time outliers for a given type of stimuli for a given participant ranged between 0 and 2. First mean reaction times across the different stimulus types are compared across participants (Fig. 6). Next, differences in reaction times between stimulus types are examined for each patient (Fig. 7).

For each case, reaction time responding to each type of stimulus was compared with that of the control group using a modified $t$ test described by Crawford and Howell (1998), which treats each individual case as a sample of $n=1$. For each stimulus type, we first assessed whether control group performance followed a normal distribution by testing for skew and kurtosis. Crawford et al. (2006) performed simulations for the modified $t$ test under conditions of skewness and kurtosis, and found that the method 


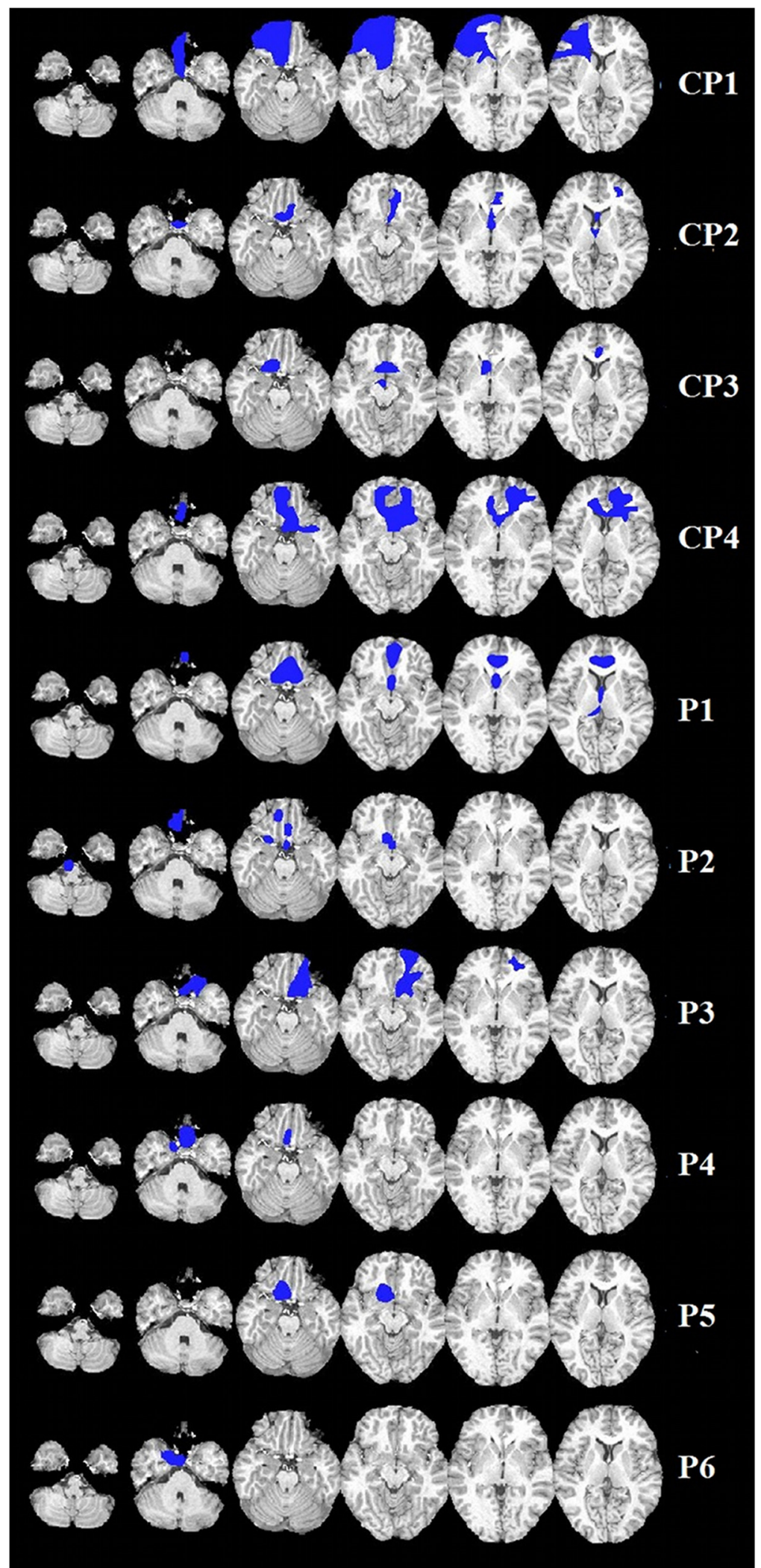

Figure 4. Patient frontal lobe brain lesions. Slices are $8 \mathrm{~mm}$ apart at $z=-30,-22,-14,-6,+2$, and +10 .

ered moderate to severe skew, and a kurtosis value is considered moderate or severe if it deviates from that of the normal distribution by $>2$ (where a normal distribution has a value of 3 ).

For all stimulus types except for Part 2 current schema words, there was significant positive skew in the control group, so a threshold of $p<0.02$ was used to evaluate significance for reaction time in response to these stimulus types. Note that there was also moderate kurtosis for previous schema (old) words.

In Parts 1 and 2, CP1, CP2, CP3, and CP4 had significantly greater reaction times in responding to current schema words than did the healthy control group $\left(\right.$ Part 1: $t_{(11)}=4.120, p=0.001 ; t_{(11)}=$ $8.855, p=0.000 ; t_{(11)}=7.650, p=0.000$; $t_{(11)}=14.620, p=0.000$; Part 2: $t_{(11)}=$ $6.960, p=0.000 ; t_{(11)}=11.025, p=0.000$; $t_{(11)}=9.162, p=0.000 ; t_{(11)}=16.352$, $p=0.000$; Fig. 6). CP1, CP2, and CP4 had significantly longer reaction times in responding to irrelevant words in Part 1 $\left(t_{(11)}=5.454, p=0.000 ; t_{(11)}=4.524, p=\right.$ $\left.0.000 ; t_{(11)}=9.408, p=0.000\right)$, and in Part 2, all four patients with present or former confabulation differed from the control group $\left(t_{(11)}=5.918, p=0.000\right.$; $t_{(11)}=6.488, p=0.000 ; t_{(11)}=2.468, p=$ $\left.0.016 ; t_{(11)}=12.920, p=0.000\right)$. Additionally, in Part 2, CP1, CP2, CP3, and $\mathrm{CP} 4$ had significantly longer reaction times than the control group in responding to both previous schema words (old: $t_{(11)}=$ 4.032, $p=0.001 ; t_{(11)}=9.442, p=0.000$; $t_{(11)}=6.249, p=0.000 ; t_{(11)}=15.016, p=$ 0.050 ; new: $t_{(11)}=3.896, p=0.001 ; t_{(11)}=$ 3.742, $p=0.002 ; t_{(11)}=10.496, p=0.000$; $\left.t_{(11)}=6.368, p=0.000\right)$.

Of the six nonconfabulating ACoA patients, only P6 differed significantly from the control group in terms of reaction time on the tasks, and this was only in response to Part 2 current schema words $\left(t_{(11)}=2.736, p=\right.$ 0.010).

Additional comparisons between reaction time measures within a specific case were conducted using the Revised Standardized Difference Test (RSDT) by Crawford and Garthwaite (2005). The RSDT tests whether the standardized difference between a patient's score on one measure and the score on another measure is significantly different from the difference between these measures in a healthy control group. Differences in reaction time were

remains robust even under extreme cases, leading them to suggest that when control data are not normally distributed, a more stringent $p$ value $(p<0.02)$ on a one-tailed $t$ test should be used. This is the method that we have applied. As in the study by Crawford et al. (2006), a skew statistic $>0.30$ or less than -0.30 was consid- compared between the following pairs of stimulus types: Part 2 irrelevant words and previous schema (old) words (Fig. 7A), Part 2 irrelevant words and previous schema (new) words (Fig. 7B), and previous schema (old) words and previous schema (new) words (Fig. 7C). Considering the significantly skewed distribu- 


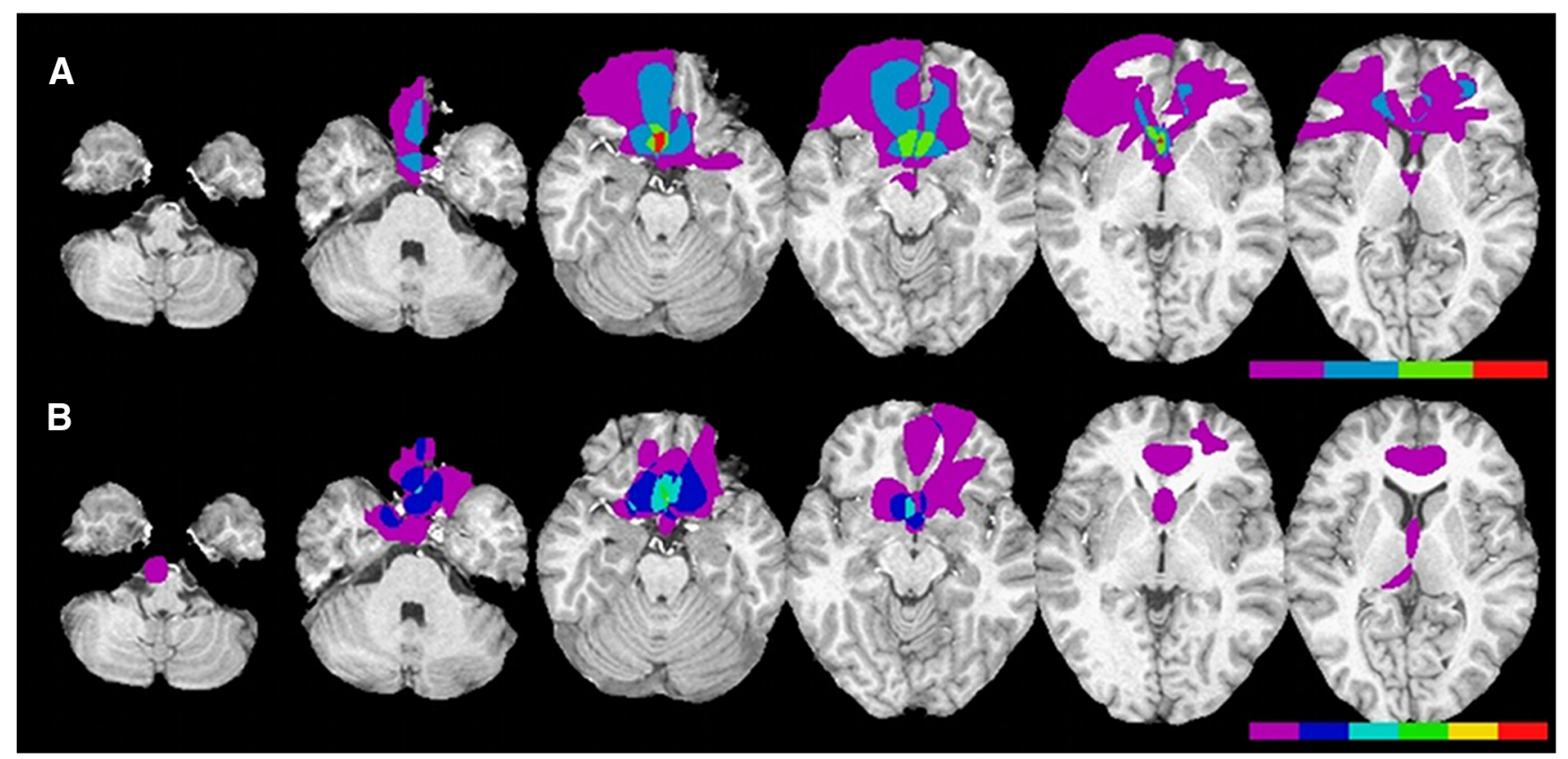

Figure 5. Patient lesion comparisons. Slices are $8 \mathrm{~mm}$ apart at $z=-30,-22,-14,-6,+2$, and +10 . $A$, Lesion overlap of CP1, CP2, CP3, and CP4. Purple indicates regions damaged in only one patient, blue indicates regions damaged in two patients, green indicates regions damaged in three patients, whereas red indicates overlap in all four patients. $\boldsymbol{B}$, Lesion overlap of P1-P6. The color bar indicates the number of patients with damage to a particular area, where purple represents regions damaged in only one patient, blue represents regions damaged in two patients, etc.

tion of reaction time in the control group, a significance threshold of $p<0.02$ was used for these comparisons.

For patients P1- P6, differences in reaction time across stimulus types were comparable to those of the control group. $\mathrm{CP} 2$, $\mathrm{CP} 3$, and $\mathrm{CP} 4$ differed significantly from the control group in the relative difference for them to reject previous schema (old) words than other irrelevant words $\left(t_{(11)}=10.128, p=0.000 ; t_{(11)}=8.138\right.$, $\left.p=0.000 ; t_{(11)}=13.464, p=0.000\right)$. The reaction time difference to reject previous schema (new) words versus other irrelevant words was also significantly greater for $\mathrm{CP} 3\left(t_{(11)}=9.822, p=0.000\right)$ and $\mathrm{CP} 4\left(t_{(11)}=4.880, p=0.000\right)$ than for the control group.

It is interesting to note that although $\mathrm{CP} 3$ and $\mathrm{CP} 4$ show some of the longest response times on the schema task, their processing speed as measured by TMT A, TMT B, Stroop Words, and Stroop Colors, is within normal range. $\mathrm{CP} 1$ and $\mathrm{CP} 2$ are impaired on the TMT but intact on the 45 s Stroop. Conversely, patient P6, who has normal reaction times on the schema task, demonstrates impaired processing speed on the TMT and on color naming on the Stroop. Thus, it is unlikely that the deficits on the schema tasks are attributable to overall processing speed deficits in the confabulating patients.

Three of the confabulating patients (CP2-CP4) also differed significantly from the control group in terms of the reaction time difference to reject previous schema words, whether old or new. For $\mathrm{CP} 3$, this was manifested by longer reaction times to reject previous new, than old, schema words $\left(t_{(11)}=8.138, p=0.000\right)$. In contrast, for $\mathrm{CP} 2$ and $\mathrm{CP} 4$, this was reflected by longer reaction times to reject previous schema old, than new, words $\left(t_{(11)}=\right.$ $10.128, p=0.000 ; t_{(11)}=13.464, p=0.000$ ).

None of the other patients differed significantly from the control group in terms of reaction time differences across stimulus types.

\section{Accuracy}

Figure 8 depicts accuracy of each of the patients compared with the control group on the task. Accuracy of the control group had a significant negative skew across all stimulus types, and severe kurtosis for Part 1 current schema and irrelevant words, as well as for Part 2 irrelevant words. As a result, the single-subjects onetailed $t$ test was used to compare the difference in accuracy of each case to the control group, using a threshold of $p<0.02$ to determine significance. Upon closer inspection, it was found that there was an extreme ceiling effect for irrelevant words, such that any deviation from perfect accuracy deemed a patient as performing significantly differently from the control group. Specifically, for Part 1 irrelevant words, 9 of 12 control participants had perfect accuracy, with the three remaining participants making one to three errors. For Part 2 irrelevant words, one control participant made one error, whereas the rest performed with perfect accuracy. As a result, even accounting for skew, statistical tests cannot be conducted to compare patient performance to that of the control group for this stimulus type. Mean scores of patients making $>3$ errors ( $<90 \%$ accuracy) are reported below.

$\mathrm{CP} 1$ performed more poorly than did the control group on Part 1 irrelevant words (mean accuracy $=63 \%$ ), Part 2 current schema words $\left(t_{(11)}=-5.444, p=0.000\right)$, Part 2 irrelevant words (mean accuracy $=77 \%$ ), and previous schema (new) words $\left(t_{(11)}=-3.225, p=0.000\right)$. CP4 had poor accuracy on current schema $\left(t_{(11)}=-5.604, p=0.000\right)$ and irrelevant words (mean accuracy $=80 \%)$ in Part 1 , and on Part 2 current schema words $\left(t_{(11)}=-8.647, p=0.000\right)$. CP2 and $\mathrm{CP} 3$ did not differ from the control group in terms of accuracy.

P4 had accuracy that was below that of the control group's on both current schema $\left(t_{(11)}=-5.124, p=0.000\right)$ and irrelevant (mean accuracy $=63 \%$ ) words in Part 1 . Note that she did not differ from control participants in accuracy in responding to the other types of stimuli. Her relatively poor accuracy on Part 1 then may reflect that her schema for "going to bed at night", the first schema presented, differs significantly from that of the control participants, as she both included irrelevant words in this schema and excluded relevant words. No other ACoA control patient differed from the control group in terms of accuracy. 

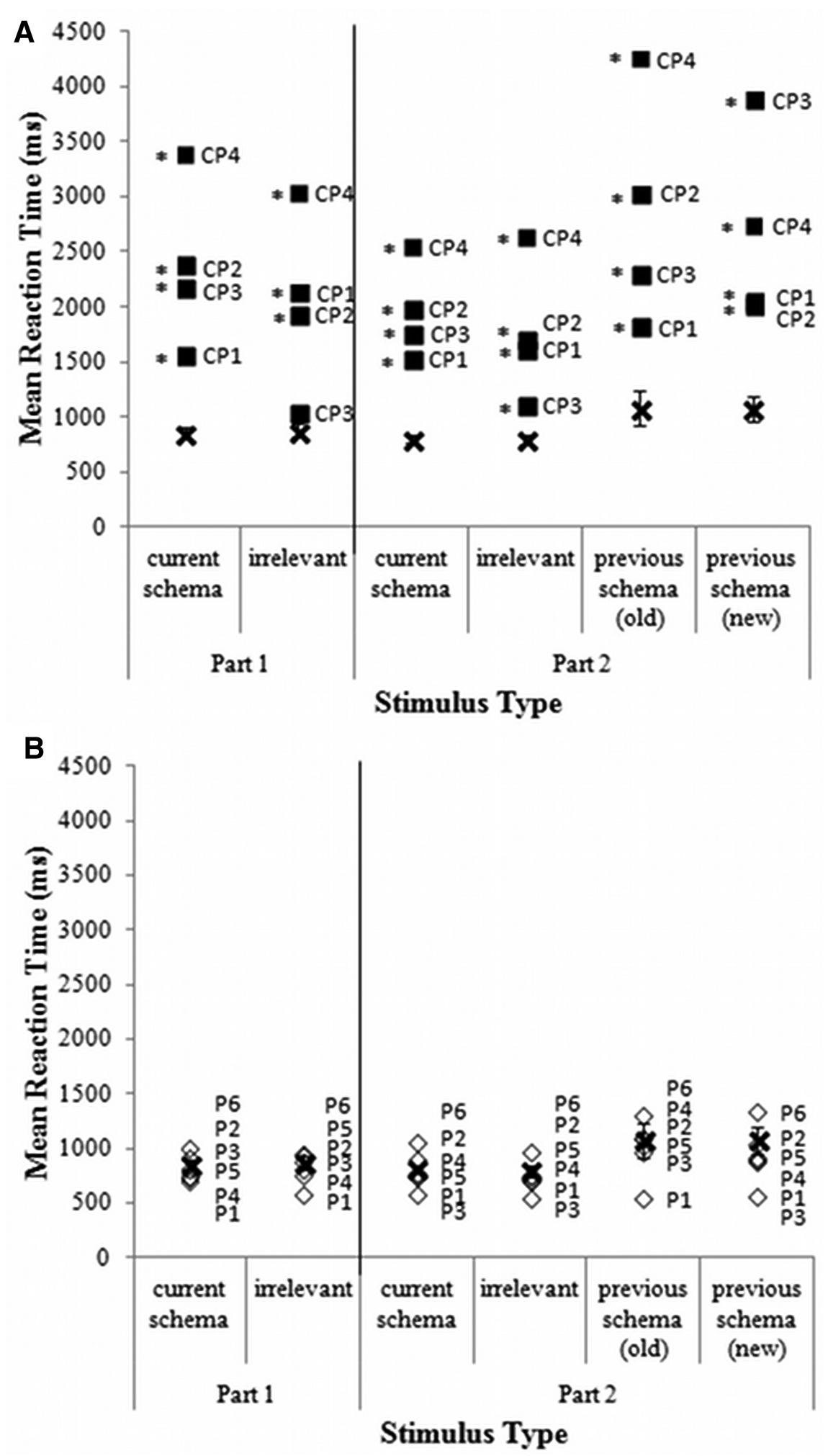

Figure 6. Task reaction times. $\boldsymbol{A}$, depicts reaction time performance of patients with present or former confabulation, whereas $\boldsymbol{B}$, depicts reaction time performance of nonconfabulating ACoA patients. An " $\mathrm{x}$ " represents mean reaction time of the healthy control group. Error bars represent SEM. Asterisks indicate patients whose reaction time in responding to a certain stimulus type differed significantly from the control group $(p<0.02)$.

Relation of reaction time to accuracy

As illustrated above, the confabulating patients differed from the control group on several measures of accuracy and reaction time. Interestingly, they also appear to have differed from one another.
For instance, although CP3 differed substantially from the control group in terms of reaction time, he did perform at an extremely high level in terms of accuracy; whereas CP1 performed significantly worse than the control group in terms of accuracy across several stimulus types. To probe these differences, the relationship between accuracy and reaction time was examined for previous schema words (old and new words collapsed together; Fig. 9). The relationships between reaction time and accuracy could not be examined for current schema words and irrelevant words as there was not an accuracy distribution in the confabulating patients, as two of them had the same accuracy score and there are only four patients. Furthermore, the results could not be interpreted for nonconfabulating ACoA patients either, as most performed near ceiling along with the healthy control group. When responding to previous schema words in Part 2, it appears that for the patients with confabulation, as accuracy increases, there is an associated increase in reaction time, indicating that they need more time to achieve a level of accuracy. Such a relationship is not evident in the nonconfabulating patients. For $\mathrm{CP} 1, \mathrm{CP} 2, \mathrm{CP} 3$, and $\mathrm{CP} 4$, however, also associated with the increase in accuracy and reaction time, is a decrease in total number of erroneous details on the Crovitz cue-word task (Fig. 2).

\section{Ratings}

The participant ratings corroborate the accuracy findings in that $\mathrm{CP} 1, \mathrm{CP} 2$, and CP4 had difficulty excluding irrelevant and/or previous schema words from their current schema (see analyses below). ACoA control patients included more irrelevant words than did the control group, but not more schema lures. Additionally, the ratings illustrate that the confabulating patients do not demonstrate higher false alarms on the task due to a bias toward responding "yes", but rather that their inclusion of irrelevant and previous schema words falls on an association gradient (Fig. 10).

The average rating of association given by each patient was compared with that of the healthy control group using the modified $t$ test described by Crawford and Howell (1998). Previous schema words were collapsed into one category containing both old and new words, as both sets of words had been seen in Part 2, meaning that they can no longer be distinguished in this manner. Control group ratings distribution of current schema words had significant skew and kurtosis, and therefore, the threshold for significance used was $p<0.02$. For previous schema words, the significance threshold was $p<0.05$. 


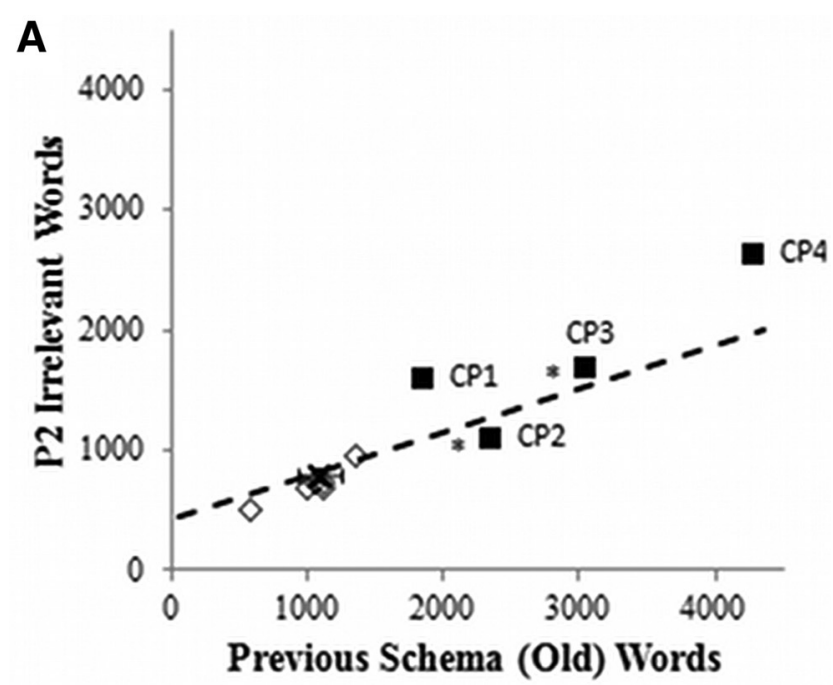

B

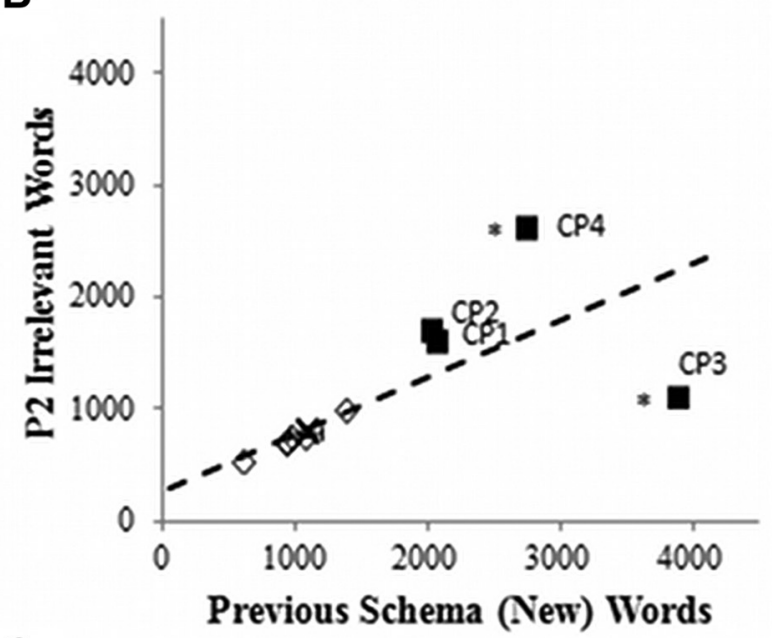

C

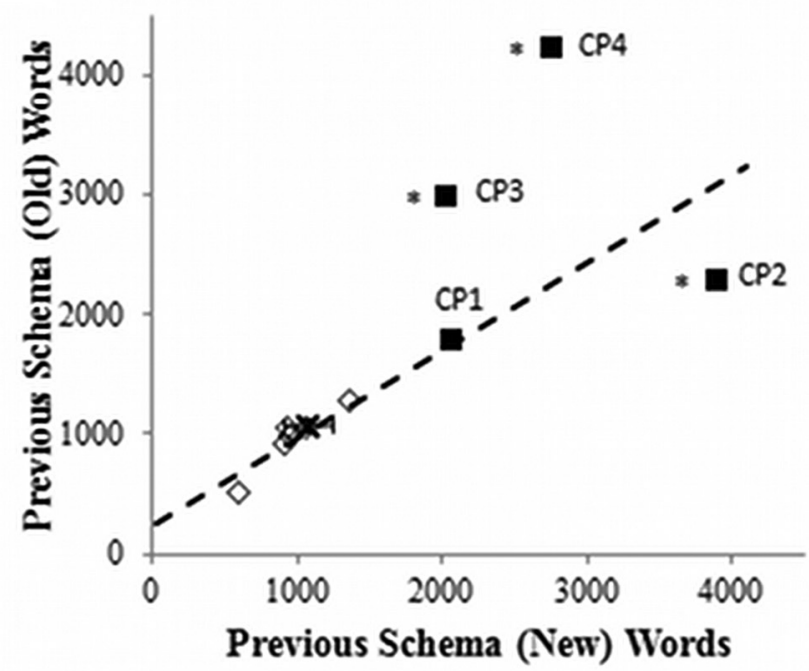

Figure 7. Reaction time comparisons across stimulus types in Part 2.A, Irrelevant vs previous schema old lures, $\boldsymbol{B}$, Irrelevant vs previous schema new lures, $\boldsymbol{C}$, Previous schema old vs. new lures. Stars indicate a patient whose difference between reaction times is significantly different from that of the healthy control group $(p<0.02)$. An " $x$ " represents the mean of the control group, whereas each diamond represents a nonconfabulating $\mathrm{ACOA}$ patient, and each black square represents a confabulating patient. Error bars indicate SEM. The dotted lines represent the trend line of the healthy control group. "P2" indicates Part 2 of the task.
The three currently confabulating patients $(\mathrm{CP} 1, \mathrm{CP} 2$, and $\mathrm{CP} 4)$ rated previous schema words as significantly more related to the current schema than did healthy controls $\left(t_{(11)}=-5.409\right.$, $\left.p=0.000 ; t_{(11)}=-3.630, p=0.002 ; t_{(11)}=-3.985, p=0.001\right)$. One ACoA control patient, $\mathrm{P} 6$, also rated previous schema words as significantly more related to the current schema than did the control group $\left(t_{(11)}=-1.850, p=0.046\right)$.

For irrelevant words, there was an extreme ceiling effect, rendering any deviation from perfect performance to be deemed significantly poorer than the control group. Specifically, 11 of 12 control subjects gave every irrelevant word a rating of " 4 ." The remaining participant gave all irrelevant words, save for one a rating of " 4 ." As a result, even accounting for skew, statistical tests cannot be conducted to compare patient performance to that of the control group, and thus the results will be presented qualitatively instead. Three of the patients' mean ratings of irrelevant items were $<3.9$ ( $\mathrm{CP} 1, \mathrm{CP} 2$, and $\mathrm{P} 1)$. However, the mean rating of $\mathrm{CP} 2$ and $\mathrm{P} 1$ were still $>3.5$, and thus close to 4 . $\mathrm{CP} 1$ had a mean rating of 3.1, and thus demonstrates the greatest deviation from control group performance.

Differences in ratings of current schema stimuli and previous schema lures within each case were compared with those differences in the control group using the RSDT by Crawford and Garthwaite (2005). Again, considering the significantly skewed distribution of ratings of current schema stimuli in the control group, a significance threshold of $p<0.02$ was used for these comparisons. None of the nonconfabulating ACoA patients differed from the healthy control group on this measure. However, $\mathrm{CP} 1\left(t_{(11)}=4.035, p=0.001\right), \mathrm{CP} 2\left(t_{(11)}=2.477, p=0.015\right)$, and $\mathrm{CP} 4\left(t_{(11)}=2.540, p=0.014\right)$ had significantly more similar ratings for current schema stimuli and previous schema lures than did the control group.

\section{Discussion}

This study provides the first demonstration that vmPFC damage, when associated with confabulation, leads to significant impairments in processing schema-related information even when memory is not tested. ACoA patients with present or former confabulation were generally impaired on fundamental level schema processing and in rejecting prior schema lures when minimal construction effort and no episodic memory demands were present. Nonconfabulating ACoA patients performed comparably to healthy controls, with high accuracy and similar reaction time profiles.

Previous studies that implicated the vmPFC in schema effects on memory did not examine its role in schema processing itself. Neuroimaging memory studies examined vmPFC contributions to encoding (van Kesteren et al., 2010; Tse et al., 2011; Kumaran, 2013), retrieval (Wang et al., 2012), inference (Zeithamova and Preston, 2010), and decision making (Kumaran et al., 2009). Rat lesion studies found that the mPFC is critical for schemafacilitated memory formation (Tse et al., 2011). We show here that the human vmPFC not only participates in mediation of schema effects on memory, but also that under certain conditions vmPFC lesions can lead to core impairment in schema processing.

Two alternative mechanisms may underlie this core, schemaprocessing impairment. It could be that vmPFC damage leads to a more nebulous schema structure; that is, schema-related concepts are not well differentiated from unrelated concepts with respect to the strength of association between them (cf. idea of Shallice and Cooper (2012) for latching across attractor memory basins). The vmPFC could act as a hub binding together schemarelated concepts, similar to the role proposed for the anterior 


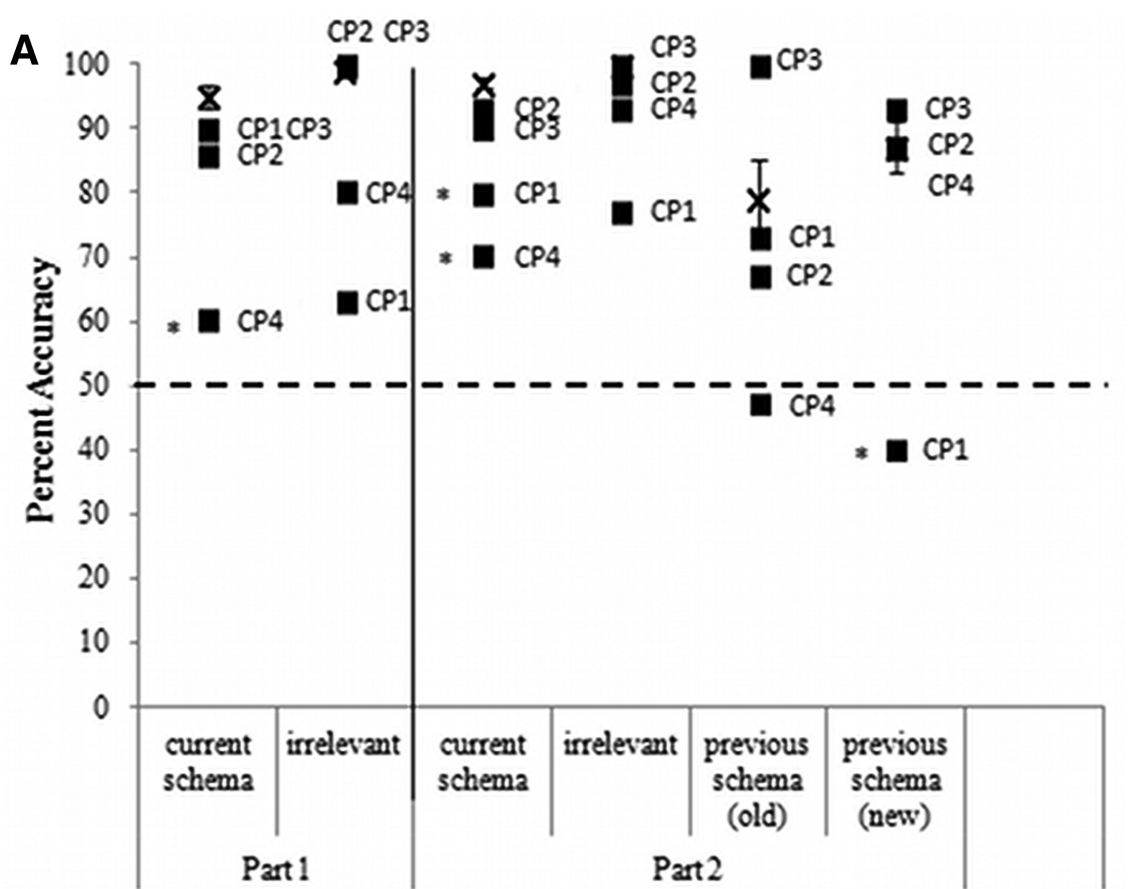

Stimulus Type

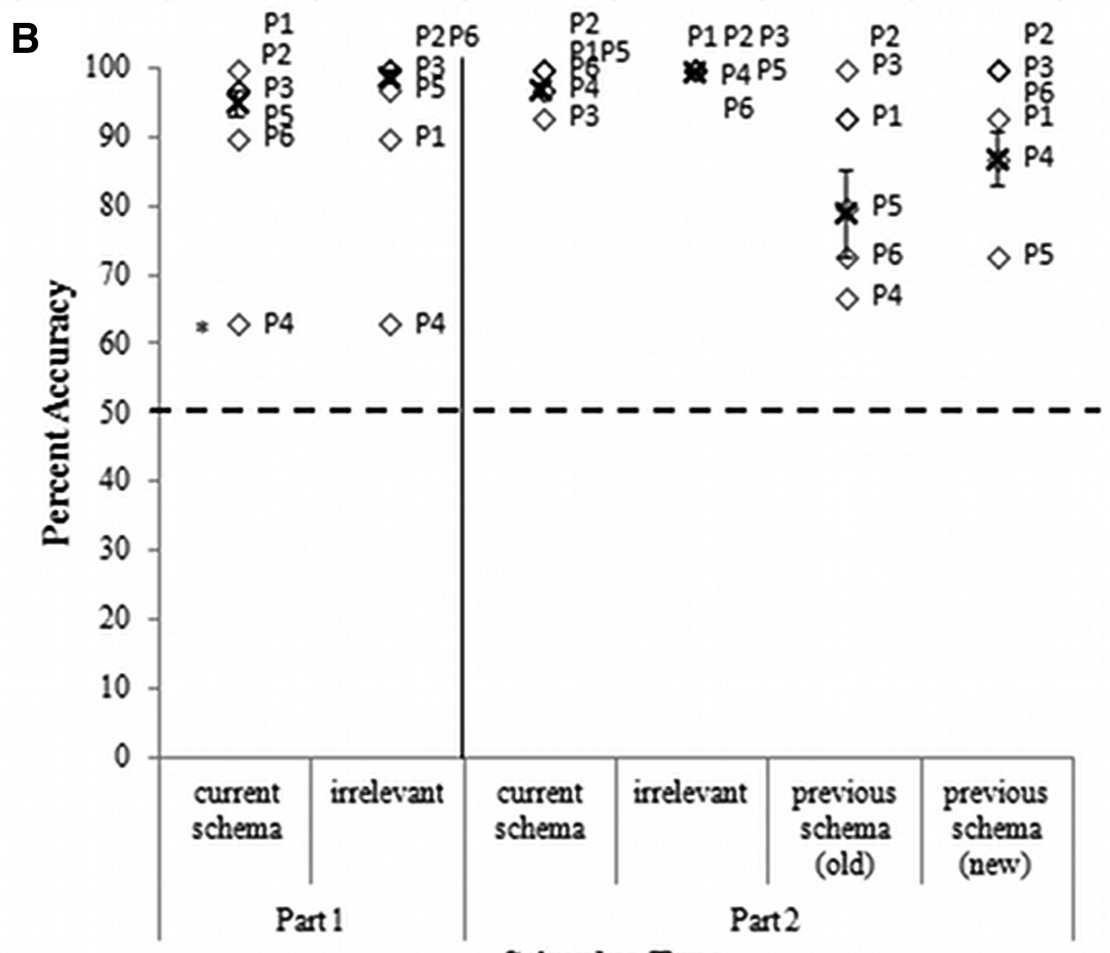

Stimulus Type

Figure 8. Task accuracy. $\boldsymbol{A}$ depicts reaction time performance of patients with present or former confabulation, whereas $\boldsymbol{B}$ depicts reaction time performance of nonconfabulating $A C O A$ patients. An " $x$ " represents the mean accuracy of the healthy control group. Error bars represent SEM. Asterisks indicate a patient whose accuracy differs significantly from that of the healthy control group $(p<0.02)$. Note that performance on irrelevant words was analyzed qualitatively, and not statistically, due to extreme ceiling effects.

temporal lobe in conceptual representations (Patterson et al., 2007) and the hippocampus in episodic memory. This would explain why those patients demonstrating deficient schema processing exhibited longer reaction times both when responding to items that should be included in the schema and to items that should be excluded (Fig. 6). It may also account for the finding that the relationship between stimulus type and reaction time to reject an item differed between the confabulating vmPFC patients and the control group (Fig. 7). Furthermore, this "nebulous schema" interpretation is also consistent with findings that the vmPFC participates in integration of new information into existing schemas (van Kesteren et al., 2010, 2012; Tse et al., 2011).

A second alternative is that the $\mathrm{vmPFC}$ critically supports inhibitory processes that help constrain the instantiation of schemas to include relevant concepts only. Schema representations were vulnerable to inclusion of concepts from a related, but inappropriate, schema. By that account, elongated response times in accepting schema-relevant concepts in Part 1 may reflect difficulty distinguishing related concepts from potential lures. Similar mechanisms have previously been proposed in other conceptual domains, for example in refractory access dysphasia (Crutch and Warrington, 2005). The ratings data also more strongly support this inhibitory alternative than the nebulous schema interpretation. All ACoA patients, confabulating patients included, were able to appropriately rate current schema items as highly related to the current schema, whereas only confabulating patients were more inclusive, rating lures as more related than did the healthy controls (Fig. 10). Deficient suppression of irrelevant schemas is also congruent with Schnider's proposal (Schnider et al., 2002; Schnider, 2008) that vmPFC neurons suppress the influence of currently irrelevant thought on memory and behavior.

Inhibitory deficits could present a mechanism for the proposal that vmPFC lesions result in failure to automatically monitor and detect erroneous memories (Moscovitch and Winocur, 2002; Gilboa et al., 2006). Plausibility of candidate memories are verified against existing schemas (Gilboa, 2004); failure to inhibit irrelevant schemas following vmPFC damage could result in highly inclusive templates at monitoring and lead to acceptance of erroneous memories.

Importantly, the link between vmPFC damage and impaired schema processing is not obligatory. Most vmPFC patients demonstrated schema processing comparable to healthy controls; only patients with current or previous confabulation were significantly impaired. This may reflect a lack of sensitivity of our task, as healthy controls were at ceiling on several measures and perhaps milder forms of schema instantia- 
tion deficits in nonconfabulating vmPFC patients could not be observed. Alternatively, it could be that there is a true functional dissociation related to confabulatory status and different schema functions, as discussed below.

The manner in which vmPFC mediates schema reinstatement may differ from the way it mediates the influence of schemas on memory and decisions, where only the latter has been the subject of prior studies in this area (Kumaran et al., 2009; van Kesteren et al., 2010; Tse et al., 2011; Wang et al., 2012; Kumaran, 2013). In prior studies, vmPFC lesions have been found paradoxically to reduce susceptibility to conceptual, gist-induced memory intrusions using the Deese-Roediger-McDermott memory paradigm. This was demonstrated in patients with memory impairment and confabulation (Melo et al., 1999), and in those with preserved memory function where confabulation is not reported (Warren et al., 2014). Gist and schema share important attributes (e.g., associative network structure) but also differ on important dimensions (e.g., gist memory is extracted from a single, not multiple episodes, and its components are specific rather than general details; Ghosh and Gilboa, 2014). Nonetheless, it is possible that the nonconfabulating ACoA patients who were capable of representing a schema in the present experiment would be impaired when applying their schemas to facilitate memory acquisition or retrieval. A related interpretation is that damage to the vmPFC, with or without confabulation, impairs the ability to extract gist-based or schema-based information from exemplars. This is consistent with the finding by Gilboa et al. (2006) that both confabulating and nonconfabulating ACoA patients demonstrate difficulty distinguishing between targets and samecategory lures. However, only confabulating patients produced bizarre intrusions when repeating fairy tales, presumably failing to exclude irrelevant information activated by a general fairy tale or story-telling schema.

Confabulation is the primary memory disorder that arises following vmPFC damage (Gilboa and Moscovitch, 2002; Schnider, 2003; Turner et al., 2008) and tight links between schema and confabulation have been previously suggested (Burgess and Shallice, 1996; Gilboa et al., 2006, 2009). It is currently unknown why some patients with vmPFC damage confabulate, and others do not. Although vmPFC damage appears to be necessary for confabulation and schema deficits, additional damage not evident on neuroimaging, perhaps due to hydrocephalus or vasospasm, may also contribute or be required. Thus, although damage to subgenual vmPFC appears to be necessary for confabulation (Schnider, 2003; Gilboa et al., 2006; Turner et al., 2008), other factors may play modulating roles, including damage to white matter or other anterior limbic system structures (Schnider, 2003), as well as dynamic factors, such as metabolic disruptions (Box et al., 1999) or neurocognitive compensatory processes (Gilboa, 2010). Either way, the neuroanatomical and neurofunctional determinants of confabulation appear closely related to those that mediate the relationship between subgenual vmPFC and core schema processing. Accordingly, the same issues in interpreting structure-function relationships that have been documented in the previous literature pertaining to confabulation apply to these new findings on vmPFC implication in schema function.

Further corroborating the relationship between the anatomical determinants of confabulation and schema processing, the patients' degree of confabulation was associated with their degree of difficulty excluding items from their schemas. The patient demonstrating the most severe confabulation ( $\mathrm{CP} 1)$, made the greatest number of lure-exclusion errors, whereas $\mathrm{CP}$, with only a history of confabulation, performed with high accuracy. CP2 and CP4 fell between these two patients both in terms of degree of confabulation as quantified by the Crovitz cue-word test, and in terms of schema lure accuracy. Interestingly, CP3's high accuracy came at a cost of extremely long reaction times, suggesting he used effortful compensatory strategies that may also support his recovered ability to verify erroneous memories or avoid reporting them (Gilboa, 2010).

The vmPFC is heterogeneous, comprising distinct limbic and cortical components with complex connectivity and interactions with distinct neural systems (Barbas, 2007). It may have a dual role, both in constraining schema instantiation and in mediating schema effects on ongoing memory processing. The vmPFC's connections to the hippocampus and other limbic system structures may be key to its contribution to memory formation and systems consolidation (Nieuwenhuis and Takashima, 2011; van Kesteren et al., 2012). Conversely, it may support constrained instantiation of context-relevant schemas by biasing posterior neocortical representation through its connections with highorder association cortices (Gilboa et al., 2009; van Kesteren et al., 2012). The vmPFC exerts early top-down modulation of higher 


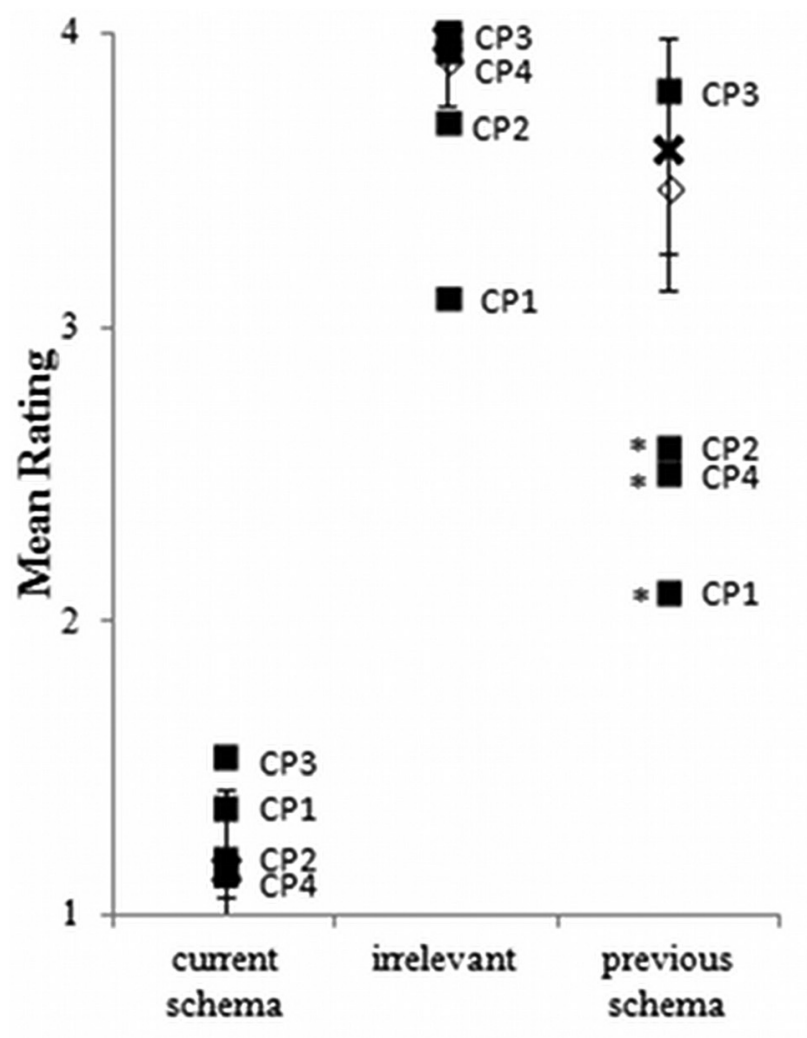

Stimulus Type

Figure 10. Mean ratings of degree of association to the Part 2 schema. Black squares represent confabulating patients, white diamonds represent the mean of nonconfabulating ACOA patients, whereas $x^{\prime}$ s represent mean ratings of the control group. Error bars represent SEM. Asterisks indicate patients whose ratings of association of a certain stimulus type differed significantly from that of the control group $(p<0.02)$. Note that performance on irrelevant words was analyzed qualitatively, and not statistically, due to extreme ceiling effects. Note that a rating of 1 denotes a word that is highly associated to the "doctor" schema, whereas a rating of 4 denotes a word that is weakly associated to the "doctor" schema.

order perceptual cortices that biases processing of environmental stimuli based on long-term contextual representations (Bar et al., 2006). Moreover, a combined lesion-electrophysiological study demonstrated that vmPFC lesions interfere with a very early posterior neocortical electrophysiological signature (N170) involved in remote memory for faces, and alter the ability to rapidly bias posterior neocortical long-term representations in the service of memory decisions (Gilboa et al., 2009). Such mechanisms may underlie the activation and selection of appropriate schemas that serve as templates during memory construction and reconstruction.

In conclusion, damage to the subgenual vmPFC produces deficits in constraining schema instantiation to only include relevant concepts under certain conditions. Specifically, difficulty in restricting schema flexibility in patients with vmPFC lesions is associated with a greater tendency to confabulate.

\section{References}

Bar M, Kassam KS, Ghuman AS, Boshyan J, Schmidt AM, Dale AM, Hämäläinen MS, Marinkovic K, Schacter DL, Rosen BR, Halgren E (2006) Topdown facilitation of visual recognition. Proc Natl Acad Sci U S A 103: 449-454. CrossRef Medline

Barbas H (2007) Flow of information for emotions through temporal and orbitofrontal pathways. J Anat 211:237-249. CrossRef Medline

Bartlett FC (1932) Remembering: a study in experimental and social psychology. New York: Cambridge UP.
Berlyne N (1972) Confabulation. Br J Psychiatry 120:31-39. CrossRef Medline

Box O, Laingl H, Kopelman M (1999) The evolution of spontaneous confabulation, delusional misidentification and a related delusion in a case of severe head injury. Neurocase 5:251-262. CrossRef

Burgess PW, McNeil JE (1999) Content-specific confabulation. Cortex 35: 163-182. CrossRef Medline

Burgess PW, Shallice T (1996) Confabulation and the control of recollection. Memory 4:359-411. CrossRef Medline

Carmichael L, Walter A, Hogan H (1932) An experimental study of the effect of language on the reproduction of visually perceived form. J Exp Psychol 15:73-86. CrossRef

Craik F, Lockhart R (1972) Levels of processing: a framework for memory research. J Verbal Learn Verbal Behav 11:671-684. CrossRef

Crawford JR, Garthwaite PH (2005) Testing for suspected impairments and dissociations in single-case studies in neuropsychology: evaluation of alternatives using Monte Carlo simulations and revised tests for dissociations. Neuropsychology 19:318-331. CrossRef Medline

Crawford JR, Howell DC (1998) Comparing an individual's test score against norms derived from small samples. Clin Neuropsychol 12:482486. CrossRef

Crawford JR, Garthwaite PH, Azzalini A, Howell DC, Laws KR (2006) Testing for a deficit in single-case studies: effects of departures from normality. Neuropsychologia 44:666-677. CrossRef Medline

Crutch SJ, Warrington EK (2005) Abstract and concrete concepts have structurally different representational frameworks. Brain 128:615-627. CrossRef Medline

Damasio H, Damasio A (1989) Lesion analysis in neuropsychology. New York: Oxford UP.

Delis DC, Freeland J, Kramer JH, Kaplan E (1988) Integrating clinical assessment with cognitive neuroscience: construct validation of the California verbal learning test. J Consult Clin Psychol 56:123-130. CrossRef Medline

Fastenau PS, Denburg NL, Hufford BJ (1999) Adult norms for the reyosterrieth complex figure test and for supplemental recognition and matching trials from the extended complex figure test. Clin Neuropsychol 13:30-47. CrossRef Medline

Ghosh VE, Gilboa A (2014) What is a memory schema? A historical perspective on current neuroscience literature. Neuropsychologia 53:104-114. CrossRef Medline

Gilboa A (2004) Autobiographical and episodic memory: one and the same? Evidence from prefrontal activation in neuroimaging studies. Neuropsychologia 42:1336-1349. CrossRef Medline

Gilboa A (2010) Strategic retrieval, confabulations, and delusions: theory and data. Cogn Neuropsychiatry 15:145-180. CrossRef Medline

Gilboa A, Moscovitch M (2002) The cognitive neuroscience of confabulation: a review and a model. In: Handbook of memory disorders, Ed 2 (Baddeley AD, Kopelman MD, Wilson BA, eds), pp 315-342. London: Wiley.

Gilboa A, Verfaellie M (2010) Telling it like it isn't: the cognitive neuroscience of confabulation. J Int Neuropsychol Soc 16:961-966. CrossRef Medline

Gilboa A, Alain C, Stuss DT, Melo B, Miller S, Moscovitch M (2006) Mechanisms of spontaneous confabulations: a strategic retrieval account. Brain 129:1399-1414. CrossRef Medline

Gilboa A, Alain C, He Y, Stuss DT, Moscovitch M (2009) Ventromedial prefrontal cortex lesions produce early functional alterations during remote memory retrieval. J Neurosci 29:4871-4881. CrossRef Medline

Golden CJ (1978) Stroop Color and Word Test. Chicago: Stoelting.

Kan IP, Larocque KF, Lafleche G, Coslett HB, Verfaellie M (2010) Memory monitoring failure in confabulation: evidence from the semantic illusion paradigm. J Int Neuropsychol Soc 16:1006-1017. CrossRef Medline

Kapur N, Coughlan AK (1980) Confabulation and frontal lobe dysfunction. J Neurol Neurosurg Psychiatry 43:461-463. CrossRef Medline

Kopelman MD (1987) Two types of confabulation. J Neurol Neurosurg Psychiatry 50:1482-1487. CrossRef Medline

Korsakoff SS (1889) Etude medico-psychologique sur une forme des maladies de la memoire. Revue Philosophique 28:501-530.

Kumaran D (2013) Schema-driven facilitation of new hierarchy learning in the transitive inference paradigm. Learn Mem 20:388-394. CrossRef Medline

Kumaran D, Summerfield JJ, Hassabis D, Maguire EA (2009) Tracking the 
emergence of conceptual knowledge during human decision making. Neuron 63:889-901. CrossRef Medline

Levine B, Svoboda E, Hay JF, Winocur G, Moscovitch M (2002) Aging and autobiographical memory: dissociating episodic from semantic retrieval. Psychol Aging 17:677-689. CrossRef Medline

Melo B, Winocur G, Moscovitch M (1999) False recall and false recognition: an examination of the effects of selective and combined lesions to the medial frontal lobe/diencephalon and frontal lobe structures. Cogn Neuropsychol 16:343-359. CrossRef

Moscovitch M (1989) Confabulation and the frontal systems: strategic versus associative retrieval in neuropsychological theories of memory. In: Varieties of memory and consciousness: essays in honour of Endel Tulving (Roediger HL, Craik FIM, eds), pp 133-160. Hillsdale: Lawrence Erlbaum.

Moscovitch M, Melo B (1997) Strategic retrieval and the frontal lobes: evidence from confabulation and amnesia. Neuropsychologia 35:10171034. CrossRef Medline

Moscovitch M, Winocur G (2002) The frontal cortex and working with memory. In: Principles of frontal lobe function (Stuss DT, Knight R, eds), 188-209. New York: Oxford UP.

Nedjam Z, Dalla Barba G, Pillon B (2000) Confabulation in a patient with fronto-temporal dementia and a patient with Alzheimer's disease. Cortex 36:561-577. CrossRef Medline

Nieuwenhuis IL, Takashima A (2011) The role of the ventromedial prefrontal cortex in memory consolidation. Behav Brain Res 218:325-334. CrossRef Medline

Patterson K, Nestor PJ, Rogers TT (2007) Where do you know what you know? The representation of semantic knowledge in the human brain. Nat Rev Neurosci 8:976-987. CrossRef Medline

Periáñez J, Ríos-Lago M, Rodríguez-Sánchez JM, Adrover-Roig D, SánchezCubillo I, Crespo-Facorro B, Quemada JI, Barceló F (2007) Trail making test in traumatic brain injury, schizophrenia, and normal ageing: sample comparisons and normative data. Arch Clin Neuropsychol 22: 433-447. CrossRef Medline

Petrides M, Pandya DN (2002) Comparative cytoarchitectonic analysis of the human and the macaque ventrolateral prefrontal cortex and corticocortical connection patterns in the monkey. Eur J Neurosci 16:291-310. CrossRef Medline

Piaget J (1926) The language and thought of the child. New York: Routledge-Kegan Paul.

Schnider A (2003) Spontaneous confabulation and the adaptation of thought to ongoing reality. Nat Rev Neurosci 4:662-671. CrossRef Medline

Schnider A (2008) The confabulating mind: how the brain creates reality. Oxford UP.
Schnider A, von Däniken C, Gutbrod K (1996) The mechanisms of spontaneous and provoked confabulations. Brain 119:1365-1375. CrossRef Medline

Schnider A, Valenza N, Morand S, Michel CM (2002) Early cortical distinction between memories that pertain to ongoing reality and memories that don't. Cereb Cortex 12:54-61. CrossRef Medline

Shallice T, Cooper RP (2012) The organisation of mind. Cortex 48:13661370. CrossRef Medline

Stuss DT, Alexander MP, Floden D, Binns MA, Levine B, McIntosh AR, Rajah N, Hevenor SJ (2002) Fractionation and localization of distinct frontal lobe processes: evidence from focal lesions in humans. In: Principles of frontal lobe functions (Stuss DT, Knight RT, eds), pp 392-407. New York: Oxford UP.

Tombaugh TN, Kozak J, Rees L (1999) Normative data stratified by age and education for two measures of verbal fluency: FAS and animal naming. Arch Clin Neuropsychol 14:167-177. CrossRef Medline

Tse D, Takeuchi T, Kakeyama M, Kajii Y, Okuno H, Tohyama C, Bito H, Morris RG (2011) Schema-dependent gene activation and memory encoding in neocortex. Science 333:891-895. CrossRef Medline

Turner MS, Cipolotti L, Yousry TA, Shallice T (2008) Confabulation: damage to a specific inferior medial prefrontal system. Cortex 44:637-648. CrossRef Medline

Van Kesteren MTR, Fernández G, Norris DG, Hermans EJ (2010) Persistent schema-dependent hippocampal-neocortical connectivity during memory encoding and postencoding rest in humans. Proc Natl Acad Sci U S A 107:7550-7555. CrossRef Medline

van Kesteren MTR, Ruiter DJ, Fernández G, Henson RN (2012) How schema and novelty augment memory formation. Trends Neurosci 35: 211-219. CrossRef Medline

Wang SH, Tse D, Morris RG (2012) Anterior cingulate cortex in schema assimilation and expression. Learn Mem 19:315-318. CrossRef Medline

Warren DE, Jones SH, Duff MC, Tranel D (2014) False recall is reduced by damage to the ventromedial prefrontal cortex: implications for understanding the neural correlates of schematic memory. J Neurosci 34:76777682. CrossRef Medline

Warrington EK (1996) The Camden memory tests, Vol 1. Hove: Psychology.

Wechsler D (2001) Wechsler test of adult reading (WTAR). San Antonio: Psychological Corporation.

Wechsler D (2008) WAIS-IV administration and scoring manual. Austin: NCS Pearson.

Zeithamova D, Preston AR (2010) Flexible memories: differential roles for medial temporal lobe and prefrontal cortex in cross-episode binding. J Neurosci 30:14676-14684. CrossRef Medline 